2016 Modular and Offsite Construction (MOC) Summit

Edmonton, Alberta, Canada, September 29 - October 01, 2016

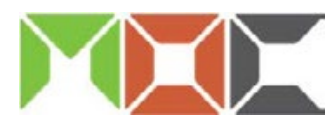

\title{
Modelling the Construction On-Site Technology Adoption Process
}

\author{
Samad M. E. SEPASGOZAR ${ }^{1 *}$ and Martin LOOSEMORE ${ }^{2}$ \\ ${ }^{1}$ Lecturer, Faculty of the Built Environment, University of New South Wales Australia \\ ${ }^{2}$ Professor, Faculty of the Built Environment, University of New South Wales Australia \\ ${ }^{*}$ Corresponding author's e-mail: samad.sepasgozar@gmail.com
}

\begin{abstract}
The global modern technology market in the construction industry is valued at billions of dollars and the approach to technology diffusion taken by vendors has a major impact on the success or failure of those technologies. While many previous studies have examined the adoption and the diffusion of information technologies, the technology diffusion process for advanced on-site equipment such as tower and mobile cranes, piling rig and concrete pumps has received little attention. Based on interviews with vendors and customers covering regions in Australia and North America, during major construction equipment exhibitions, this paper presents a new equipment technology adoption model which, for the first time, describes the relationship between customers and vendors during the on-site technology adoption process. The implications of the model for fostering new on-site technology diffusion to boost productivity are discussed.
\end{abstract}

\section{KEYWORDS}

Construction innovation; On-site technology; Adoption; Vendor; Contractors; Construction.

\section{INTRODUCTION}

Technology innovation plays an important role in maintaining competitive advantage for firms and meeting the evolving demands of industry (Damanpour, 1991; Irwin et al., 1998; Lee et al., 2002; Porter, 2008). A good example of modern technology innovation is the new Autonomous Haulage System developed by Komatsu Ltd., one of the largest construction equipment manufacturers. The system uses a high precision positioning system to control the location of the unmanned trucks and control them on predetermined courses, extending operating times, reducing manpower costs and fuel consumption and emissions. Another example is using 3D GNSS (global navigation satellite systems) with machine control systems to automatically control different functionality of excavators to automatically control the blade elevation and tilt based on the desired specification and target design data. These technologies potentially eliminate and decrease human errors affecting productivity and safety in construction sites.

These types of benefits have led to a growing focus on introducing new on-site technologies into the construction industry (e.g. Senthilkumar et al., 2010; Lu et al., 2014; Miettinen and Paavola, 2014; Skibniewski, 2014; Skibniewski, 2015; Wang and Cho, 2015). While there has been some research into the diffusion of information technologies in construction (Son et al., 2012; Lee et 
al., 2013; Singh and Holmström, 2015), there is a need to identify the process of on-site technology adoption from two perspectives: a) customers - who seek new solutions for construction purposes and make the adoption decision (Lee et al., 2002; Sepasgozar et al., 2016), and b) vendors - who use different strategies to encourage the adoption of their technologies (Sepasgozar et al., 2016). The aim of this paper is to address this gap in knowledge by exploring the process by which both vendors and customers interact during the adoption of new on-site technologies. This research is important because the construction sector globally is relatively slow to adopt new technologies compared to other sectors for a wide variety of reasons including culture, contract and procurement practices, institutional resistance to change and a lack of skills and training around new technologies change (Hardie and Newell, 2011; Milliou and Petrakis, 2011; Love et al., 2014). However, specific customer- and vendor-related attributes which might cause the relatively low of adoption have not been investigated (McCoy et al., 2010; Sepasgozar et al., 2016).

According to Rogers (2003), 'technology adoption' is the process through which a decision maker passes to reach a decision to accept or reject a new technology. In this study, 'on-site construction technology' refers to any tool, plant or equipment used for carrying out physical construction activities, and advanced technology refers to the latest models of such plant and equipment. These technologies include 3D GNSS (global navigation satellite systems) in corporation with machine control systems to automatically control and sensor based-tower crane navigation, intelligent mobile crane control and concrete pumps with a 540-degress of articulation in its fold sections.

\section{METHOD}

The research adopted an exploratory qualitative research approach which involved the immersion of the investigator-observer in seven technology exhibitions in Australia and the United States. In the exhibitions, a wide range of customers using different technologies were available, and a wide range of construction technologies were disseminated by different vendors covering regions of Australia and North America. Semi-structured interviews were undertaken with participants in different businesses including 31 customers and 33 vendors. Table 1 shows the relevant participants' attribute.

Table 1. Participants attributes.

\begin{tabular}{llc}
\hline Item & Description & Total \\
\hline Participants business & Australia & 35 \\
\cline { 2 - 3 } region & North America & 63 \\
\hline Business types & Customers & 60 \\
\cline { 2 - 3 } & Vendors & 38 \\
\hline Total participants & & 98 \\
\hline
\end{tabular}

The purpose of the interviews was to address questions such as: how customers collect and analyse information about a new technology; how customers evaluate the technology before they make the final decision; how vendors support them during this process; and which vendor activities were important and could influence their decision? 


\begin{tabular}{|c|c|c|c|}
\hline Framework development & \multicolumn{2}{|c|}{ Analysis flowchart } & Steps \\
\hline $\begin{array}{l}\text { Identify signals from } \\
\text { transcription }\end{array}$ & \multicolumn{2}{|c|}{ Start by micro analysis } & Step 1 \\
\hline $\begin{array}{l}\text { Exploring different activities at } \\
\text { the basic level }\end{array}$ & $\begin{array}{c}\bar{\gamma} \\
\text { Customers' } \\
\text { activities }\end{array}$ & $\begin{array}{l}\text { Vendors' } \\
\text { activities }\end{array}$ & \multirow[t]{2}{*}{ Step 2} \\
\hline $\begin{array}{l}\text { Classify basic activities into } \\
\text { key activities or strategies }\end{array}$ & $\begin{array}{c}\frac{\downarrow}{\text { Customers' key }} \\
\text { activities }\end{array}$ & 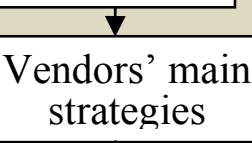 & \\
\hline $\begin{array}{l}\text { a) Developing basic themes and } \\
\text { candidate stages; b) Merge } \\
\text { related themes }\end{array}$ & \multicolumn{2}{|c|}{$\begin{array}{c}\text { Candidate stages of } \\
\text { decision making }\end{array}$} & Step 3 \\
\hline \multirow{2}{*}{$\begin{array}{l}\text { Developing the framework and } \\
\text { validation }\end{array}$} & \multirow{2}{*}{\multicolumn{2}{|c|}{$\begin{array}{c}\begin{array}{c}\text { Structure the decision } \\
\text { making framework }\end{array} \\
\text { Validation }\end{array}$}} & Step 4 \\
\hline & & & Step 5 \\
\hline $\begin{array}{l}\text { Synthesis of results for } \\
\text { developing the framework }\end{array}$ & \multicolumn{2}{|c|}{$\begin{array}{l}\text { Define three stages of } \\
\text { the framework }\end{array}$} & Step 6 \\
\hline
\end{tabular}

Figure 1. Systematic analysis flowchart to explore the model.

Figure 1 shows the six-step process of analysis of the qualitative data collected from the interviews. In Step 1, the transcriptions are coded in a systematic way resulting in the identification of passages related to adoption decision process activities. In Step 2, relevant passages are linked to nodes related to customers' and vendors' activities respectively, where each child node represents one core activity, strategy or idea. In step 3, the child nodes related to customers and vendors are allocated to 6 and 5 new parent nodes respectively and sorted into basic themes. In Step 4, a web-like map is developed reflecting parent node relationships (see Figure 2). This map visually represents parent nodes each for customers and vendors, and appears to potentially form five candidate themes. In Step 5, the candidate themes were closely examined in order to ensure that they did not overlap. The examination resulted in three coherent patterns representing the key activities that make up the adoption decision process. Step 6 involved synthesising the results of the analysis into an integrated framework.

\section{Results and discussion}

All transcripts were broken down into component parts called passages in order to classify and create meaningful concepts (Dey, 1993) from which appropriate themes were extracted. The identified passages were carefully analysed using line-by-line analysis, a process called micro analysis (Corbin and Strauss, 1994). Each passage was associated with a child node that represented the core idea. In order to increase the reliability of the results, immediate analysis of the data took place by writing memos concurrently with the coding. Charmaz (2006) recommends the memo as a useful technique for interpreting results. "Memos are the theorizing write-up of ideas about substantive codes and their theoretically coded relationships as they emerge during coding, collecting and analysing data, and during memoing" (Glaser 1998). The 
memos were written relating to the content of this paper. These memos were used as notes when the themes were developed. In order to check the interrelation and consistency of basic themes, the parent nodes were mapped into a network based on the relationships (e.g. associated and preceding) in NVivo as shown in Figure 2.

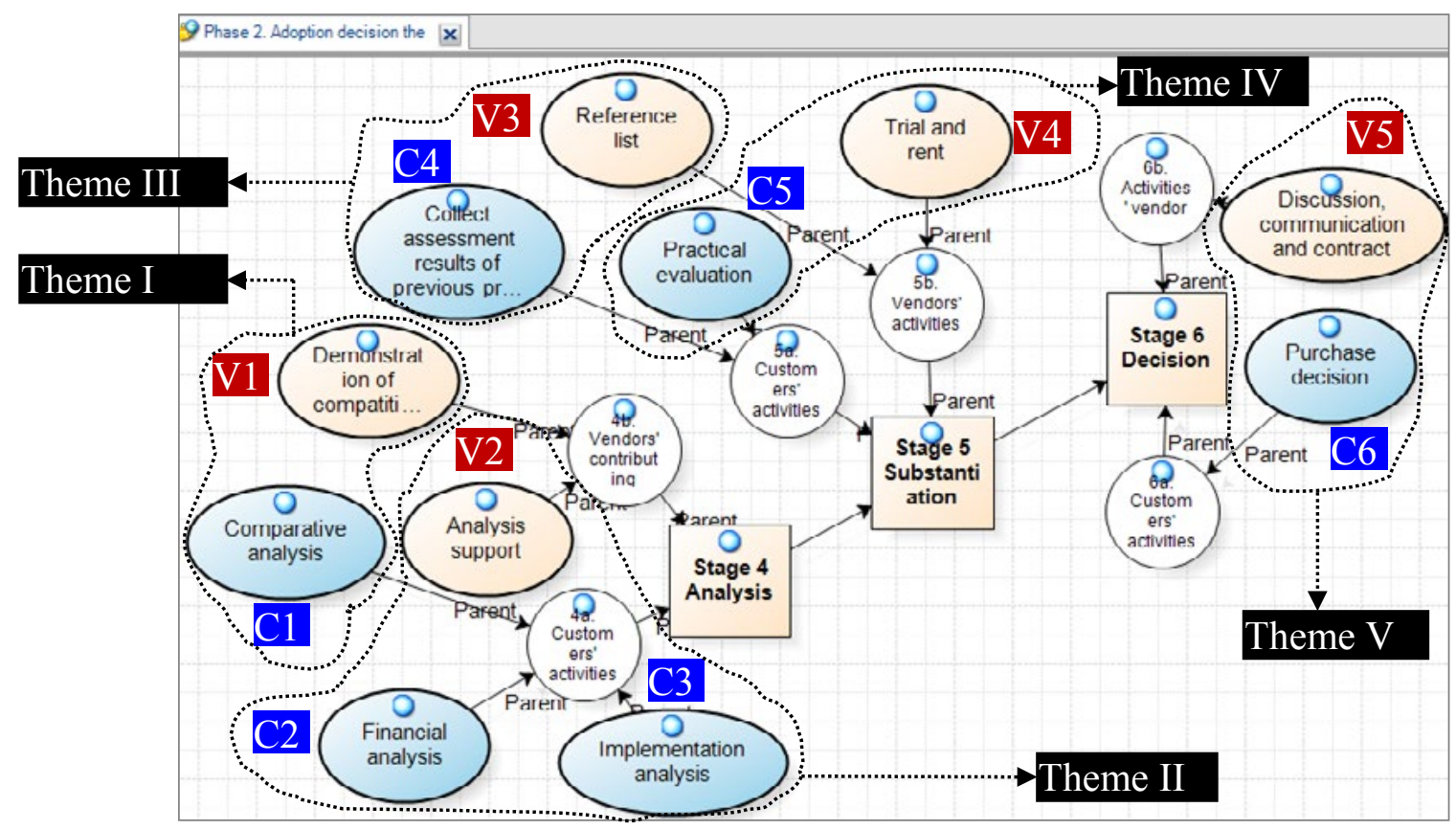

Figure 2. A thematic map showing candidate themes and sub-themes.

Note: $\mathrm{C}$ refers to basic themes related to customers. $\mathrm{V}$ refers to basic themes related to vendors.

Figure 2 illustrates five themes including eleven basic themes (e.g. C1 to C6 in blue and V1 to V5 in red), represented by their parent nodes, together with their connections. The parent nodes (basic themes) are in ellipses in the diagram and relationships are shown with arrows. The mapping exercise reveals the richness of the data's structure and its underlying patterns (AttrideStirling, 2001). It can be seen that these basic themes combine into three overarching candidate themes (Theme I to V) that correspond to potential stages in the decision making process, depicted by the three squares in the central section of the figure.

The relationships of overarching themes were then determined based on the connections between the basic themes and the thematic map. A new model was created in NVivo that includes the three overarching themes called analysis, substantiation and sales (or purchase decision) and the connections between them, see Figure 3 . 


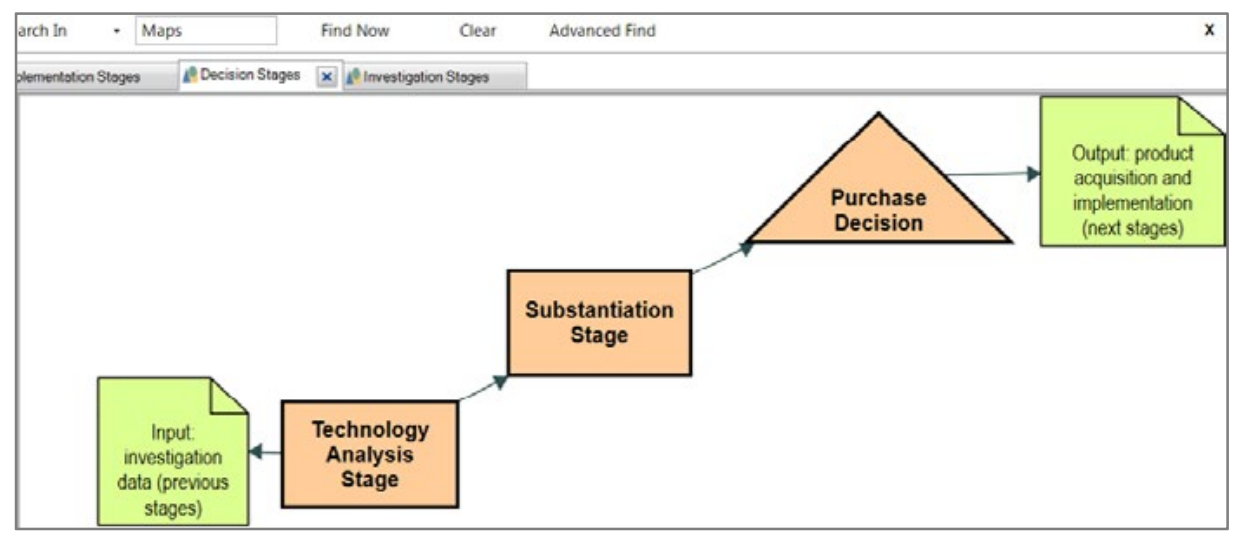

Figure 3. The model of the adoption decision.

The model shows that customers pass through three main stages (themes) to make the adoption decision: 'technology analysis', 'substantiation' and 'purchase decision'. Customers usually compare three quotes from different vendors. They tend to reject the least reliable option or often the cheapest one, and negotiate with the two others to modify terms, payment and commercial conditions. However, the cost and payment cannot be the key factor influencing their decision. A vendor manager states, based on his experience, that "It's not the cheapest that gets the order, the most reliable gets the order." Customers then communicate with the references of each vendor from similar projects in order to evaluate the technology in terms of reliability of the technology in operation by evaluating the technology's practical performance.

The results also show that vendors will focus on the following activities In Table 2:

Table 2. Selected vendor activites.

\section{Vendor activities}

Try to get short listed

Provide technical information

Quotes

Justify technology

Provide firm proposal

Answer customers' team questions

Provide evidence of money saving

Direct new customers to referees and provide

reference list

Talk and generate news about new technologies

Offer services such as lease / hire

Offer trial

Validation evidences

Offer on-site demo \& application

Assist customers in evaluating the technology

Hands on

Video demonstration

Online demo

Own practical evaluation reference
Vendors' main business strategy (Parent node)

V1. Exhibit competitive advantages

V2. Support customers in the analysis stage

V3. Provide reference list

V4. Offer trials and provide evaluation support 
Job-site demonstration

Delivery time

Proposed contract

Commercial terms and condition

Negotiation

Payment conditions

Table 2 shows that vendors support customers to collect technological specifications and detailed data about nominated technologies, they analyse them comparatively from both the technical and financial perspectives. At this stage, the vendors' role is important in terms of demonstrating the features of the technology and its value. A vendor states:

"Customers very often they ask the sub-supplier [local dealers] can you do spare and wear parts proposal for one year when the pump is working 8000 hour per year. If you [vendor] are not 100\% pushing, you will not get the order."

In the final stage of the adoption process, some customers prefer to buy a construction technology from a vendor who has local dealer and is available at any time to support them with site visits, inspections, and providing spare parts. Some customers even prefer to adapt something that their local dealer has available in store rather than choosing a new technology from a manufacturer in another country. For example, one customer states that "if our available dealer has something close" then they would "adapt" it.

The new stages and activities identified above are not evident in previous construction innovation adoption literature, illustrating the important difference between the process of adoption in information technology and onsite construction technology.

\section{CONCLUSION}

The aim of this paper was to investigate the process of decision making for adopting an on-site construction technology. It was found that the literature about the construction on-site technology adoption process concerning different key activities immediate before purchase decision is scarce. The existing studies in information technologies focuses on individuals decision acceptance which is often one single event, and ignore other key events and activities. While in Roger's diffusion theory the acceptance stage is determined as one stage occurring after "persuasion" (Rogers, 2010), the current literature does not provide any detailed information how the decision is made and how vendors support the decision maker during the decision process. The results of the analysis of semi-structured interviews with customers and vendors covering Australia and North America shows that decision process includes three distinct stages: information analysis, substantiation, and purchase decision. From the other side, vendors support the decision maker by providing specific information about their technology, offering trial and references list, and offering the firm contract of sale. These activities are very active and competitive with vendors chasing customers and negotiating with them until the customer commits. The findings of this paper were validated by data triangulation between the customer and vendor activities from two different countries.

The limitation of this research was the national context in which it occurred. Further research is required to reveal factors influencing the construction companies' decision. Some other key areas for future study could include: the effect of virtual trailing (digital) and practical evaluation 
(field) on the purchase decision; the process of implementation of new sensor-based technologies and their compatibility with information technologies; the effect of on-site technology adoption rate on off-site productivity; rentals role in the technology diffusion process at the industry level.

\section{REFERENCES}

Attride-Stirling, J. (2001) "Thematic Networks: An Analytic Tool for Qualitative Research", Qualitative Research, 1(3), 385-405.

Charmaz, K. (2006) Constructing Grounded Theory: A Practical Guide through Qualitative Analysis, London: Pine Forge Press.

Corbin, J. and Strauss, A. (1994) "Grounded Theory Methodology", Handbook of Qualitative Research, 273-285.

Damanpour, F. (1991) "Organizational Innovation: A Meta-Analysis of Effects of Determinants and Moderators", Academy of Management Journal, 34(3), 555-590.

Dey, I. (1993) Qualitative Data Analysis: A User Friendly Guide for Social Scientists, London: Routledge.

Hardie, M. and Newell, G. (2011) "Factors Influencing Technical Innovation in Construction Smes: An Australian Perspective", Engineering, Construction and Architectural Management, $18(6), 618-636$.

Irwin, J. G., Hoffman, J. J. and Lamont, B. T. (1998) "The Effect of the Acquisition of Technological Innovations on Organizational Performance: A Resource-Based View", Journal of Engineering and Technology Management, 15(1), 25-54.

Lee, E.-J., Lee, J. and Schumann, D. W. (2002) "The Influence of Communication Source and Mode on Consumer Adoption of Technological Innovations", Journal of Consumer Affairs, 36(1), 1-27.

Lee, S., Yu, J. and Jeong, D. (2013) "Bim Acceptance Model in Construction Organizations", Journal of Management in Engineering.

Love, P. E., Matthews, J., Simpson, I., Hill, A. and Olatunji, O. A. (2014) "A Benefits Realization Management Building Information Modeling Framework for Asset Owners", Automation in Construction, 37, 1-10.

Lu, Y., Li, Y., Skibniewski, M., Wu, Z., Wang, R. and Le, Y. (2014) "Information and Communication Technology Applications in Architecture, Engineering, and Construction Organizations: A 15-Year Review", Journal of Management in Engineering, 31(1).

McCoy, A. P., Badinelli, R., Koebel, C. T. and Thabet, W. (2010) "Concurrent Commercialization and New-Product Adoption for Construction Products", European Journal of Innovation Management, 13(2), 222-243.

Miettinen, R. and Paavola, S. (2014) "Beyond the Bim Utopia: Approaches to the Development and Implementation of Building Information Modeling", Automation in Construction, 43, 84-91.

Milliou, C. and Petrakis, E. (2011) "Timing of Technology Adoption and Product Market Competition", International Journal of Industrial Organization, 29(5), 513-523.

Porter, M. (2008) Competitive Advantage: Creating and Sustaining Superior Performance, NY, USA: Simon and Schuster.

Rogers, E. M. (2010) Diffusion of Innovations, New York: Free press.

Senthilkumar, V., Varghese, K. and Chandran, A. (2010) "A Web-Based System for Design Interface Management of Construction Projects", Automation in Construction, 19(2), 197-212. 
Sepasgozar, S. M. E., Loosemore, M. and Davis, S. R. (2016) "Conceptualising Information and Equipment Technology Adoption in Construction: A Critical Review of Existing Research", Engineering, Construction and Architectural Management, 23(2), 158-176.

Singh, V. and Holmström, J. (2015) "Needs and Technology Adoption: Observation from Bim Experience", Engineering, Construction and Architectural Management, 22(2), 128-150.

Skibniewski, M. J. (2014) "Information Technology Applications in Construction Safety Assurance", Journal of Civil Engineering and Management, 20(6), 778-794.

Skibniewski, M. J. (2015) "Research Trends in Information Technology Applications in Construction Safety Engineering and Management", Frontiers of Engineering Management, 1(3), 246-259.

Son, H., Park, Y., Kim, C. and Chou, J.-S. (2012) "Toward an Understanding of Construction Professionals' Acceptance of Mobile Computing Devices in South Korea: An Extension of the Technology Acceptance Model", Automation in Construction, 28(0), 82-90.

Wang, C. and Cho, Y. K. (2015) "Smart Scanning and near Real-Time 3d Surface Modeling of Dynamic Construction Equipment from a Point Cloud", Automation in Construction, 49, 239249. 